\title{
Effectiveness of acceptance and commitment therapy on differentiation of self, body dissatisfaction and negative evaluation in women of visiting beauty centers
}

\author{
Maryam Bani Torfi ${ }^{1}$, Rezvan Homaei ${ }^{2}$ \\ 1-MA. Psychology, Department of Psychology, Ahvaz Branch, Islamic Azad University, Ahvaz, Iran. \\ 2- Assistance Professor, Department of Psychology, Ahvaz Branch, Islamic Azad University, Ahvaz, Iran \\ (Corresponding Author). \\ E-mail: homaei@iauahvaz.ac.ir
}

Received: 23/08/2020 Accepted: 07/11/2020

\begin{abstract}
Introduction: The rate of cosmetic surgery is increasing and it is necessary to pay attention to its common factors.

Aim: This study aims to examine the effect of the acceptance and commitment therapy on differentiation of self, body dissatisfaction and negative evaluation in women of visiting beauty centers.

Method: The research design was a semi-experimental research with pre-test and post-test with control group. Population were all the women of visiting beauty centers in 2018 in Ahvaz which of them 30 women participated based on targeted sampling method and they arranged in two groups experimental group (15 women) and Control group (15 women). After that two groups were assessed in pre-test exam. After discussion, treatment based on the acceptance and commitment (ACT) was performed during nine sessions in a week. Measurement tools consisted of Differentiating of self Inventory, body dissatisfaction Inventory and Negative Evaluation Scale. The data was analyzed by SPSS-20 and analysis of variances of multiple variables measures.

Results: The results of intergroup showed that differentiation of self, body dissatisfaction and negative evaluation were significantly different in the experimental group compared with the control group $(\mathrm{P}<0.05)$. Acceptance and commitment-based therapy increases self-differentiation and reduces anxiety about body deformity and negative evaluation $(\mathrm{P}<0.05)$.
\end{abstract}

Conclusion: According to therapeutic elements of acceptance and commitment therapy, acceptance and commitment therapy could be effective method to correct the factors that affect the performance of cosmetic surgery.

Keywords: Acceptance and commitment therapy, Differentiation of self, Body dissatisfaction, Fear of negative evaluation, Women of visiting beauty centers

How to cite this article : Bani Torfi M, Homaei R. Effectiveness of acceptance and commitment therapy on differentiation of self, body dissatisfaction and negative evaluation in women of visiting beauty centers. Shenakht Journal of Psychology and Psychiatry. 2020; 7 (5): 130144 .URL: http://shenakht.muk.ac.ir/article-1-793-en.pdf

Copyright $\odot 2018$ the Author (s). Published by Kurdistan University of Medical Sciences. This is an open access article distributed under the terms of the Creative Commons Attribution-Non Commercial License 4.0 (CCBY-NC), where it is permissible to download, share, remix, transform, and buildup the work provided it is properly cited. The work cannot be used commercially without permission from the journal. 


\title{
اثربخشى درمان مبتنى بر يذيرش و تعهد بر تمايز يافتكى خود، نكرانى از بدريختى بلدن

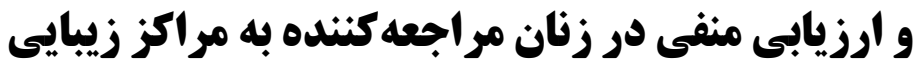

\author{
مريم بنى طرفى'، رضوان همائى \\ ا. كارشناسى ارشد روانشناسى، گروه روانشناسى، واحد اهواز، دانشكاه آزاد اسلامى، اهواز، ايران.

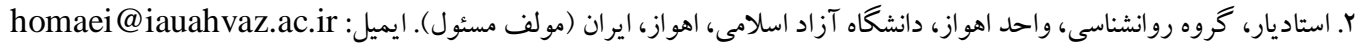

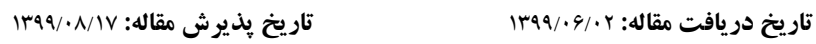

جكيده مقدمه: ميزان انجام جراحى زيبايى رو به افزايش است و توجه به عوامل رواج آن ضرورت دارد. هدف: اين بثزوهش با هدف تعيين تأثير درمان مبتنى بر بذيرش و تعهل بر تمايزيافتكى خود، نگگ انى از بدريختى بدن و ارزيابى منفى در

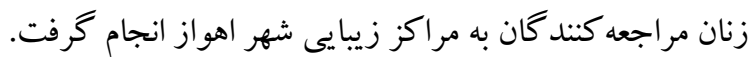

روش: طرح يزوهش از نوع نيمه آزمايشى با طرح بيش آزمون و بس آزمون با گروه كنترل استفاده شد. نمونه مورد بررسى ·ـ نفر از

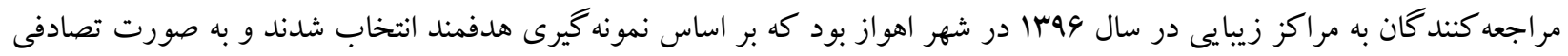

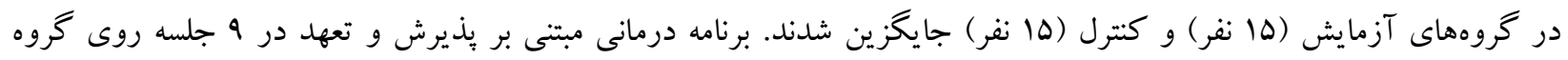

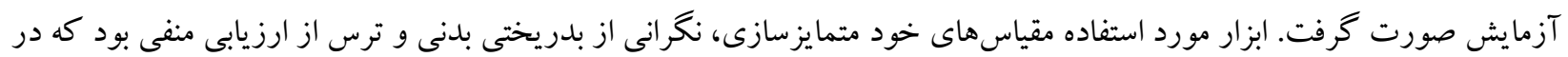

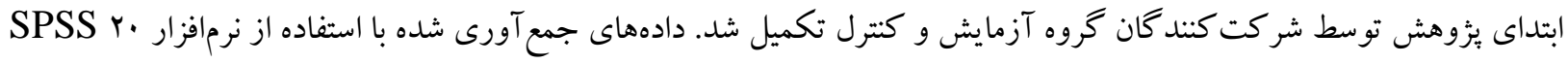
و به روش تحليل واريانس جند متغيرى مورد تجزيه و تحليل قرار گرفت

يافته ها: نتايج بين گروهى نشان داد كه تمايزيافتگى خود، نگگ انى از بدريختى بدن و ارزيابى منفى در افراد گروه آزمايش در مقايسه با

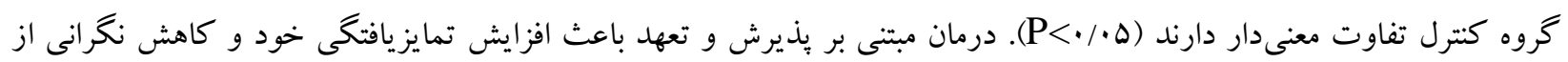

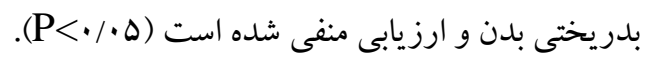
نتيجه كيرى: با توجه به عناصر درمانى درمان مبتى بر بذيرش و تعهد مى تواند روش مناسبى براى اصلاح عوامل مؤثر بر انجام جراحى زيبايى باشد. كليدوازهها: درمان مبتنى بر بذيرش و تعهد، تمايزيافتكى خود، نخرانى از بدريختى بدن، ترس از ارزيابى منفى، مراجعه كنند گان به مراكز زيبايى 
نيمرخ شخصيتى هر فرد، يكى از عوامل مهم در

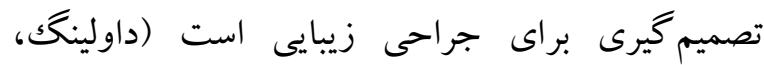

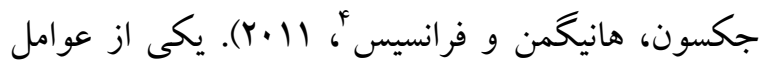
تأثير كذار از خودتوصيفى بدنى ميزان خود متمايزسازىه هايه افراد است. افراد تمايزيافته تعريف مشخصى از خود دارند و در موقعيتهاى شديداً عاطفى، كه در بسيارى از افراد منجر به بروز رفتارهاى غيرعادى و كرفتن تصميمات نافرجام مىشود، كنترل خود را از دست نداده و با در نظر كرفتن عقل و منطق تصميم گيرى مى كنند (اسكورون و و

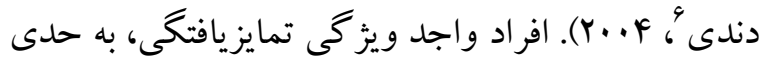
از بلوغ عاطفى رسيدهاند كه قادر به كنترل روابط باشند

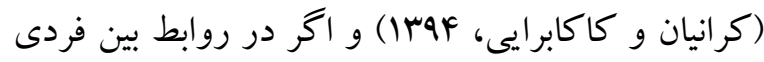
آنان مشكلى ييش بيايد، فعالانه به حل مشكل مى يردازند و نيازى نمىبينند كه براى حل اين مشكلات، به راهبردهاى ناساز كارانهاى جون تغيير شكل بدنى خوده،

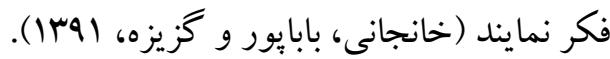
يكى ديخر از عوامل مؤثر در انجام جراحى زيبايى، بائل

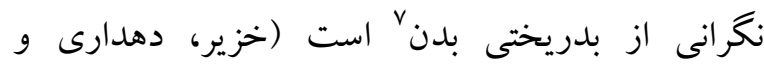

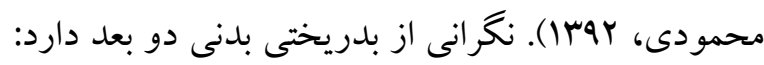
ادراكى و ارزيابى. بعد ادراكى اشاره دارد به اينكه فرد تا جه اندازهاى شايستگى او با ظاهرش سنجيده مىشود و بعد ارزيابى، به رضايت فرد از ظاهر بلدنى وى اشاره دارد

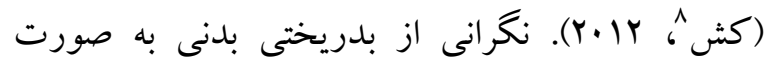
فعالانه بر رفتار، عزت نفس و مشكلات روانشناختى فرد

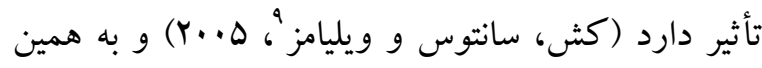
دلايل افراد به راهكارهايى نظير اقدام به اعمال جراحى
از دلايلى كه افراد از جمله زنان متحمل جراحىهاى زيبايى مىشوند اغلب اوقات عزت نفس بايين و فقدان تصورات مثبت از خود، بدريختى بدنى يا كسب توجه

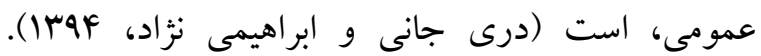
ارزيابىهاى منفى و عزتنفس يايين مادران مىتواند

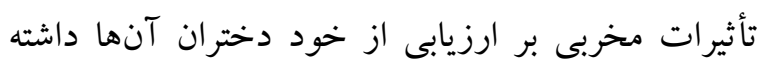
باشد؛ بنابراين اهميت به سلامت زنان در ارتقاء سلامت

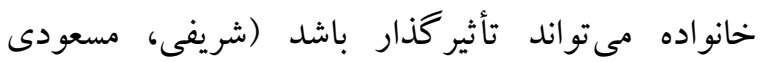

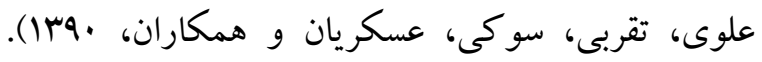
تحقيقات نشان داده كه زنان بيش از مردان به جراحى زيبايى تمايل دارند جرا كه زنان بدن خود را به عنوان يكك جسم بررسى مى كنند و زيبايى ظاهرى بدنشان برايشان اهميت دارد، درحالى كه مردان تمركزشان بر كارآمد بودن عملكرد بدنشان است و كمتر به زيبايى ظاهرى آن اهميت مىدهند (للييوسكا، لييوسكى،

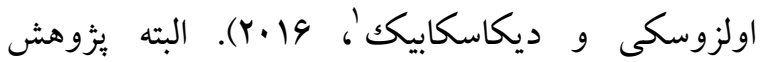

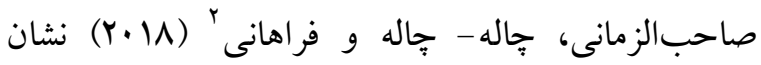
مى دهد كه عمل زيبايى در افزايش رضايت جنسى زنان مؤثر است؛ ولى در افزايش عزت نفس و رضايت جنسى همسر تأثيرى ندارد. از آنجا كه افراد، اغلب انتظارات غيرواقعى در مورد نتايج عمل جراحى زيبايى دارند و انتظار دارند كه اين جراحى، به عنوان راه حل براى مشكلات در ساير حوزههاى زندگى باشد، اغلب از نتايج عمل جراحى خود نارضايتى دارند (علوى، كلافى،

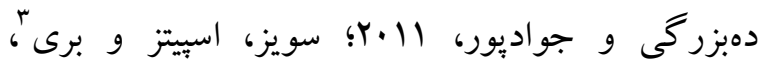
$(Y \cdot) \mathrm{V}$

\footnotetext{
1- Lipowska, Lipowski, Olszewski\&Dykalska-Bieck

2- Sahebalzamani, Chale Chale\& Farahani,

3 - Sweis,Spitz \& Barry
}

${ }^{4}$ - Dowling, Jackson, Honigman, \&Francis

5 - Differentiating of self

- Skowron \& Dnday

7 - Body dysmorphic concern

${ }^{9}$ - Cash, Santos\&Williams 
در آميختخى شناختى است تا فرد به اين مفهوم بیى ببرد كه

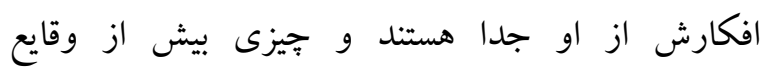
خصوصى موقت نيستد. بذيرش به معناى ايجاد فضايى براى يذيرفتن احساسها، اميال و ديخر تجربههاى خصوصى ناخوشايند، بدون تلاش براى تغيير آنها، فرار

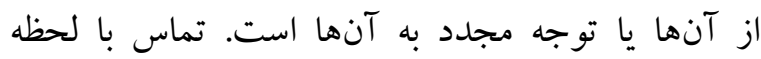
حاضر عبارت است از آوردن كامل آكاهى به تجربه

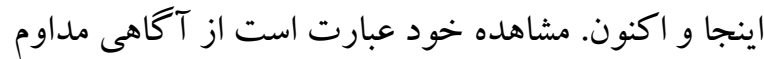
نسبت به خود كه تغيير نمى كند و هميشه حاضر و در

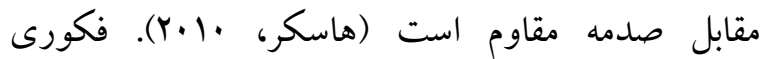

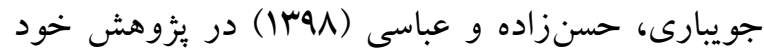

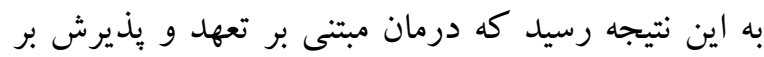

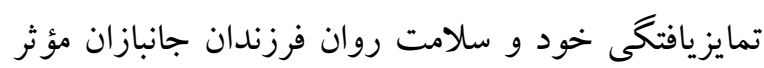

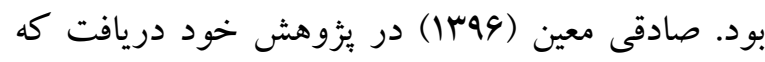

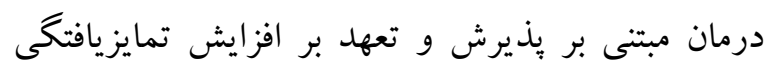
دانشجويان تأثير دارد. حبيب اللهى و سلطانى زاده (1FqF) در بزوهش خود نشان دادند كه درمان مبتنى بر بذيرش و تعهد منجر به كاهش معنادار نارضايتى بدنى و ترس از

$$
\text { ارزيابى منفى در نوجو انان مىشود. }
$$

اثرات گسترش نامطلوب جراحىهاى زيبايى، زيربنايى

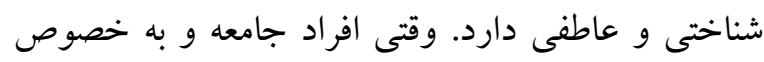
جوانان نتواند از طريق توانايىهاى شخصى خود مورد

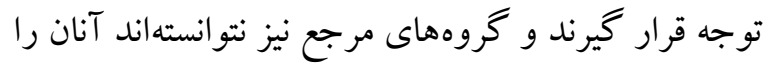
در شناخت هويت خود يارى كنند، به اين ترتيب ظاهرى ترين لايه هويت هر فرد جنان برجسته مىشود كه

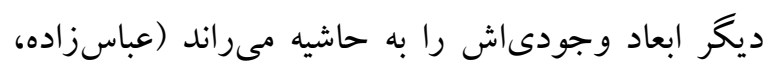

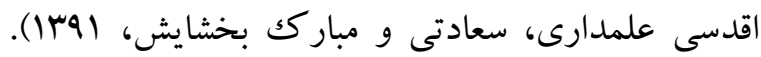
اثربخشى اين درمان به طور مستقيم در متقاضيان جراحى لئى زيبايى بررسى نشده است و با توجه به يزوهشهاى درهاي
زيبايى مىنمايند (عباس، كوكو اغلو، آيتاب يويسال و

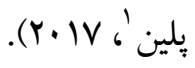
از جمله اختلالات رايج در متقاضيان جراحىهاى يلاستيك، اختلال اضطراب اجتماعى و ترس از ارزيابى

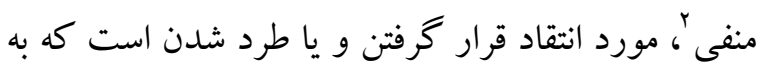
به دنبال آن فرد به اجتناب مفرط از موقعيتهاى اجتماعى رو مى آورد (آزالى علمدارى، آذريان، قربانزاده و خوشنويس، هوب(ا). اجتناب و عدم حضور در اجتماع به دليل ترس از ارزيابى منفى مىتواند به منفعل شدن ختم شود. اين افراد از تماس فيزيكى با ديخران اجتناب إباب مىنمايند و رفتارهاى اجتنابى براى حضور در اجتماع از خود نشان مىدهند (بريتو، ناهاس، كرداس، كاما اسكوييرا وهمكاران، 19.r). تصوير بدنى و ارزيابى خود خود به صورت منفى اين انتظار را در فرد ايجاد مى كند كه كويا ديخران نيز آنها را بهطور منفى ارزيابى مى كنند و در بى آن فرد خواستار تغيير در تصوير بدنى خود خواهد شد تا بتواند تصوير بدنى حقيقى خود را به تصوير

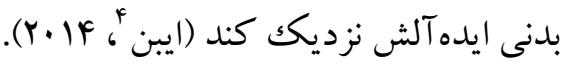

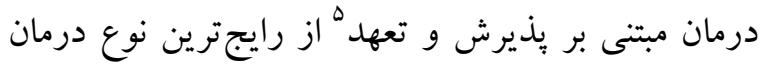
بذيرش هيجانات عاطفى و انعطافيذيرى است (كاوسيان، حريفى وكريمى، وهما). هدف اين شيوه

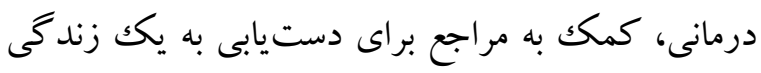

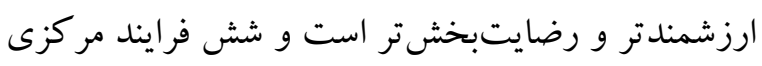

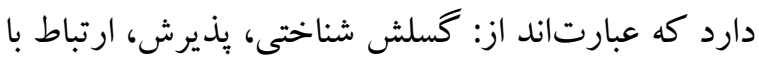
زمان حال، خود به عنوان زمينه، ارزشها و و عمل متعهدانه

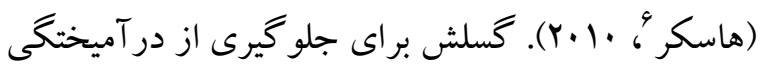

\footnotetext{
1- Abbas, Kukcuoglu, Aytop, Uysal \& Pelin

2 - Fear of negative evaluation

3 - Brito, Nahas, Cordas, Gama, Sucupira

4 - Ebben

5 - Treatment based on admission and commitment

6. Hasker
} 
تمايل به شركت در اين طرح را داشتند دعوت به عمل آمد. تعداد •ب نفر از آزمودنىها كه داراى ملاكك حضور در يُزوهش بودند، انتخاب و به صورت تصادفى دو گروه آزمايش و كنترل قرار گرفتند. در طى نمونه گيرى، به شركت كنندكان اعتماد به حدود رازدارى و محرمانه بودن اطلاعات برسشنامه و شخصى افراد داده شد و جلسه ييش آزمون با تكميل سؤالات مقياسهاى تمايزيافتخى

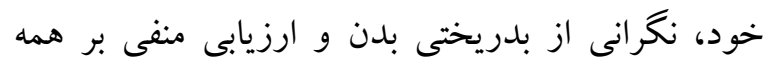

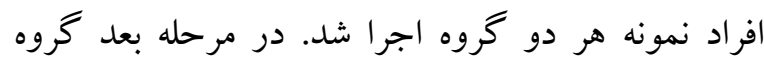
آزمايش تحت درمان مبتنى بر بذيرش و تعهد قرار گرفت

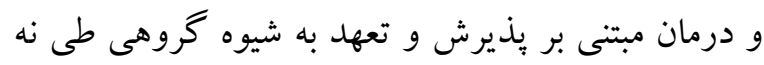
جلسه •9 دقيقهاى به صورت دو بار در هفته بر اساس

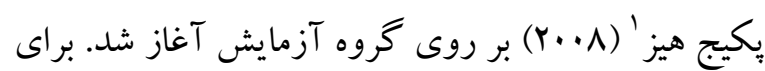
كروه كنترل يك جلسه آشنايى و مشاوره درباره جراحى زيبايى برغزار شد اما تحت هيج گونه درمانى قرار

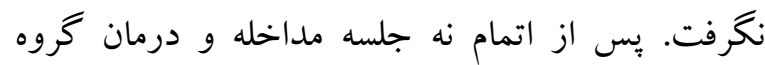

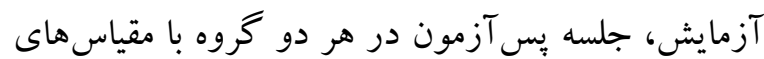

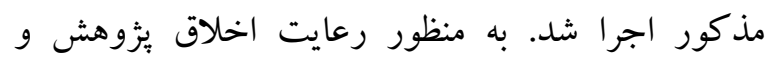
قدردانى از گرووه كنترل بعد از اتمام درمان، بيشنهاد بركزارى يكك دوره درمان مبتنى بر بذيرش و تعهد

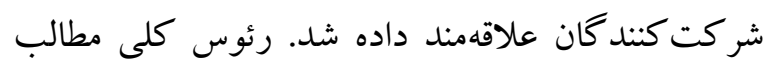
جلسات درمان در جدول | ارائه شده است. تجزيه و تحليل اطلاعات با استفاده از نرمافزار •r SPSS در دو قسمت توصيفى (شاخصهايى مانند ميانگين و انحراف معيار) و استنباطى (تحليل واريانس جندمتغيرى و يك

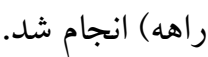

صورت گرفته و ابعاد و عناصر درمان مبتنى بر يذيرش و تعهد، اين درمان شايد بتواند در بهبود شناختى و برجسته نمودن توانمندىها و ارزشهاى وجودى زنان متقاضى

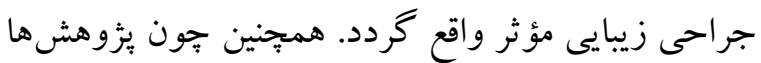
به تأثير درمان مبتنى بر تعهل و يذيرش بر درمان اضطراب،

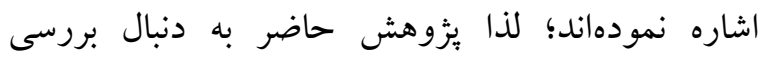
اثربخشى مداخلات درمانى مبتى بر بذيرش و تعهل بر

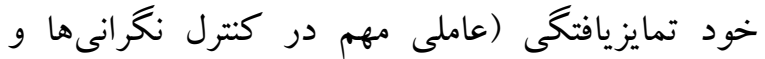
استفاده از راهبردهاى ساز كارانه در جنين موقعيتها) و نكرانى از بدريختى بدن و ارزيابى منفى در زنان مر اجعه كنند كان به مراكز زيبايى شهر اهواز بود.

روش يزوهش حاضر از نوع تحقيق نيمه تجربى و از نوع طرح

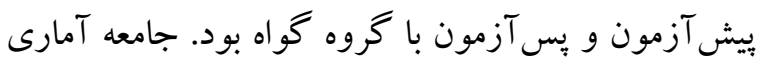
اين ئزوهش شامل كليه زنان مراجعه كنند كان به مراكز زيبايى شهر اهواز بود كه از اين بين ·r شركت كننده به صورت نمونه گيرى هدفمند انتخاب شد و به به شيوه تصادفى در دو گروه آزمايش (ها نفر) و كنترل (ها نفر ) كمارده شدند. معيارهاى ورود به مطالعه شامل رضايت كتبى براى شركت در ئزوهش، عدم وجود اختلال روانيزشكى و عدم مصرف داروهاى روانيزشكى و عدم وقوع رخداد تنشزا مانند طلاق، مرك عزيزان و غيره در شش ماه كذشته و معيارهاى خروج از مطالعه شامل دو جلسه غيبت در جلسات درمان، عدم همكارى در تكميل كردن برسشنامها و بر كردن برسشنامه به شكل نادرست و نامعتبر بود. ابتدا با مراجعه به مطب يزشكان جراحى

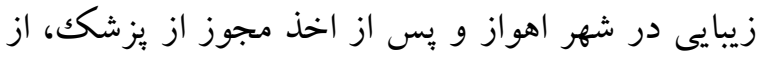
زنان متقاضى جراحى زيبايى مراجعه كننده به مركز، كه

\footnotetext{
1. Hayes
} 
جدول ا خلاصه جلسات درمان

جلسات

\begin{tabular}{|c|c|}
\hline فهم كامل ماهيت اضطراب و شناخت راهبردهاى مقابله با آن بر اساس نتايج يرسشنامه و يا هر روش ديخرى. & جلسه اول \\
\hline در نظر گرفتن كنترل به عنو ان يك مشكل، كنترل رويدادهاى شخصى و ارائه تكاليف خانگى. & 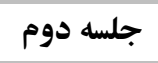 \\
\hline برداختن به تجربه مراجع و تقويت و بازشناسى او از اين موضوع كه كنترل خود معضل است. & 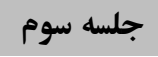 \\
\hline ايجاد يك جهت گيرى براى توسعه مهارتهاى ذهن آكاهى به عنوان جايخز ينى براى نخرانى و معرفى مفهوم & جلسه جهارم \\
\hline معرفى اهميت ارزشها و جخونكى تمايز آنها از اهداف و تعيين اهداف رفتارى ساده براى شناسايى يك رفتار & جلسه ينجم \\
\hline تداوم ايجاد يك جهت گيرى نسبت به ذهن آكاهى و ارائه شيوههاى عملى بيشتر براى برورش گسلش. & 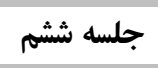 \\
\hline توجه به عملكرد هيجانات، عادت به اجتناب رفتارى و تمايز بين هيجانات واضح و مبهم. & 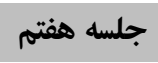 \\
\hline معرفى تمايز بين خودهاى مشاهدهگر و خودهاى مفهومى و شناسايى ارتباط بين مفهومسازىهاى خود و & جلسه هشتم \\
\hline جلسه ارائه ايده تعهل به عنوان ابزارى براى حر كت به سوى اهداف مشخص و تقويت انتخابها جهت رسيدن & جلسه نهم \\
\hline
\end{tabular}

كرونباخ محاسبه شده توسط اسكورن و فريدلندر” (M (1991)

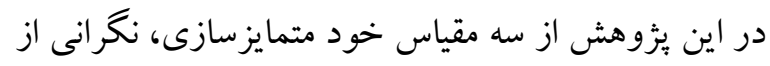

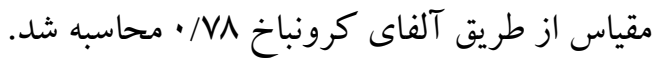
بدريختى بدنى و ترس از ارزيابى منفى استفاده شد. مقياس نترانى از تصوير بلدنى؛ اين مقياس توسط ليتلتون، مقيس خود متمايزسازى': توسط اسكورون' (Y...

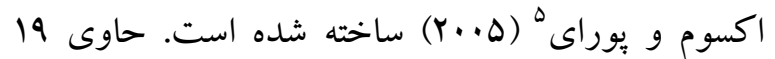

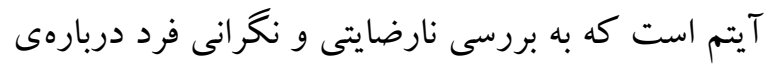
ساخته شده است، ابزارى 49 سؤالى بوده كه به به منظور

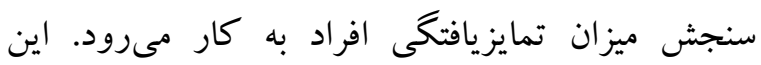
ظاهرش مى يردازد. در هاسخ به هر سؤال بايد به يك برك مقياس با مقياس ليكرت و در يكك رديف 9 كزينهاى

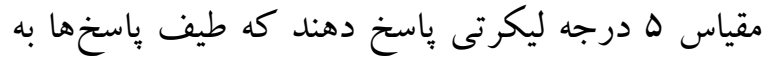
درجهبندى شده است. مقياس مذكور از ع خرده مقياس

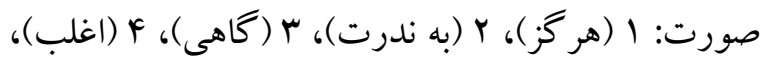

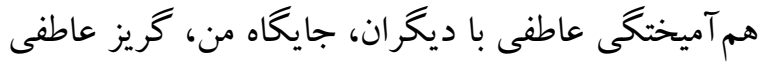
ها (هميشه) است. نمرهى كل مقياس بين 19 تا هو 9 متغير و واكنشيذيرى عاطفى تشكيل شده است. به هر سؤال بوده كه نمرات بالاتر بيانكر نارضايتى بيشتر از تصوير نمرهاى بين او 9 تعلق مى گيرد. حداكثر نمره اين مقياس بدنى است. نمره بين 19 تا حم": ميزان ترس از تصوير ظاهر

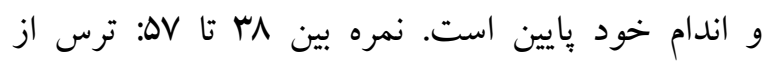
تصوير ظاهر و اندام خود متوسط است. نمره بالاتر از هV: ترس از تصوير ظاهر و اندام خود بالا است. اين ابزار دو

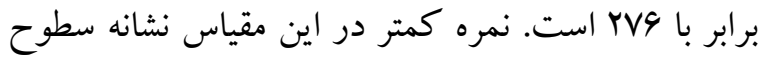

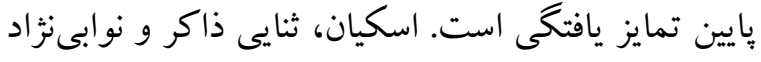
(ITAV) كرونباخ اN/· محاسبه كرده و همجنين ضريب آلفاى

3 - Friedlander

4- Body Dysmorphic Concern Inventory

5 - Littleton, Axsom \& Pury

- Differentiating of self Inventory

${ }^{2}$ - Skowron 
را توصيف مى كنند. شكرى و همكاران (IMAV) مقياس ترس از ارزيابى منفى را بر هYM دانش آموز دبيرستانى

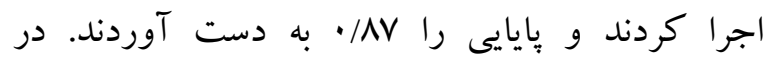
يزوهش حاضر، بايايى اين يزوهش از طريق آلفاى كرونباخ |N/ • محاسبه شد.

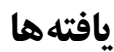

ميانگين و انحراف معيار سن كروه آزمايش به ترتيب س درگروه آزمايش ميزان تحصيلات شركت كنند كان كارشناسى، 1 نفر كارشناسى ارشد و ورهير يكك نفر نيز تحصيلات خود را ذكر نكرده بود. در گروه كنترل ميزان تحصيلات همكى افراد، كارشناسى بود. در كروه آزمايش 9 نفر از شركت كنند كان خانهدار و 9 نفر شاغل بودند. در گروه كنترل، ه نفر از شركت كنند كان

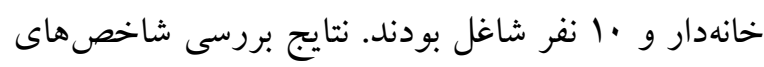
توصيفى ميانكين و انحراف نمرات خود متمايزسازى،

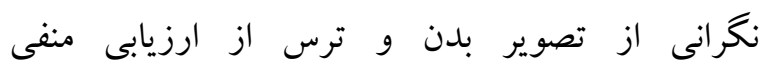
شر كت كنند گان در دو گروه آزمايش و كنترل در جدول
عامل دارد كه عامل اول نارضايتى و خجالت فرد از ظاهر خود، وارسى كردن و مخفى كردن نقايص ادراكش شده را در برمى گيرد. عامل دوم ميزان تداخل نخًانى دربارهى ظاهر را در عملكرد اجتماعى فرد نشان مىدهد. ليتلتون و

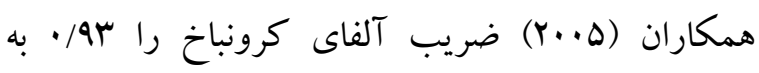
دست آوردند. محمدى و سجادى نزاد (rar) با تحليل عوامل ساختار عاملى مقياس را در دانشجويان تأييد نمودند و آلفاى كرونباخ اين مقياس را 199/ • به دست

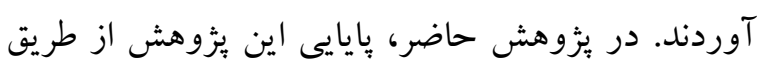
آلفاى كرونباخ /N/ • محاسبه شد. مقياس توس از ارزيابع منفى: نسخه كوتـاه مقيـاس

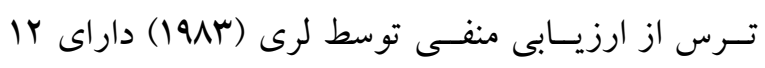
يرسـش اسـت كـهـ ميـزان اضـــراب تجربه شده افراد يا ارزيابىمنفى آنان را اندازهگيرى مى كند. اين مقياس روى يكك طيف ينجدرجهاى نمره گذارى مىشود (1) هر زز صدق نمى كند تا ها =تقريباً هميشه صدق مسى كنـد). نمرات بالاتر نشان دهنده سطوح بالاتر تجربه اضطراب و

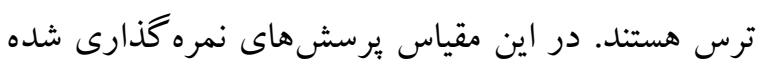
مثبت (هشت برسش) و وبرسشهاى نمره گذارى شده

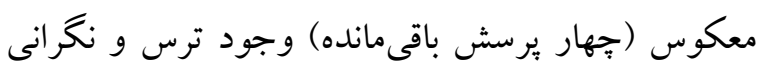

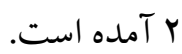

\begin{tabular}{|c|c|c|c|c|c|}
\hline \multicolumn{2}{|c|}{ 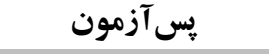 } & \multicolumn{2}{|c|}{ ييش آزمون } & \multirow[b]{2}{*}{ كروه } & \multirow[t]{2}{*}{ متغير } \\
\hline استاندارد & ميانغين & استاندارد & 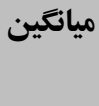 & & \\
\hline$\Delta / A V$ & $r F / Q$. & $\varphi / \Delta \mid$ & $\mu \mathrm{r} / \mathrm{\theta}$ & آزمايش & هم آميختعى عاطفى با ديكران \\
\hline$r / q 4$ & $\mathrm{rV} / \Delta$. & $P / \Delta \mid$ & $r 1 / . \Delta$ & 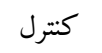 & \\
\hline$F / 9$. & kq/A. & $r / 94$ & rN/A. & آزمايش & جايگاه من \\
\hline$r / F r$ & $r V / 9 D$ & $r / \cdot v$ & $r N / Y$. & 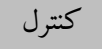 & \\
\hline$r / \Delta r$ & $r \cdot / 9$. & $r / 4 \lambda$ & $\mu 9 / \mu$. & 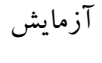 & كريز عاطفى \\
\hline$r / \Delta r$ & $r V / r$. & $r / 90$ & TV/TD & 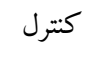 & \\
\hline$F / F Y$ & $r \cdot / q$. & $F / M F$ & $r N / \Delta r$ & آزمايش & واكنشيذيرى عاطفى \\
\hline
\end{tabular}




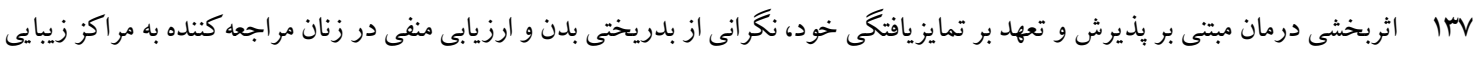

\begin{tabular}{|c|c|c|c|c|c|}
\hline$F / I V$ & $r V / r$. & r/Ar & $\mathrm{rV} / \mathrm{IS}$ & كنترل & \\
\hline$|r / r|$ & $111 / 90$ & ir & $99 / 90$ & آزمايش & نمره كل خود متمايزسازى \\
\hline IT/AF & $\Lambda \Delta / \mathcal{\epsilon}$ & W/A9 & ৭९/A. & كنترل & \\
\hline $11 / \wedge r$ & $\mathrm{FV} / \mathrm{V}$. & 11/זם & $\Delta \Delta / \wedge \Delta$ & آزمايش & نكر انى از تصوير بدنى \\
\hline Q/\% & $\Delta 9 / 1$. & $\Lambda / \wedge \Delta$ & $\Delta \varphi / \Lambda$. & كنترل - & \\
\hline$\Lambda / Y q$ & $r \cdot / v$ & $9 / 94$ & Fq/Tr & آزمايش & ترس از ارزيابى منفى \\
\hline N/99 & FA/l. & $\Lambda / V^{F}$ & FN/VI & كنترل & \\
\hline
\end{tabular}

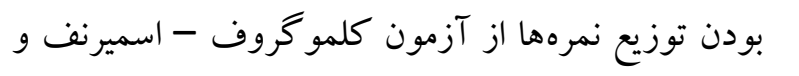
فرض برابرى واريانسها با استفاده از آزمون لوين بررسى

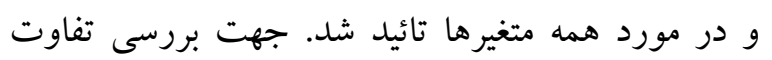

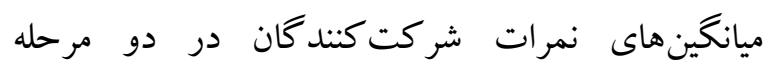
ييش آزمون و بس آزمون از تحليل آمارى كوواريانس استفاده شد. نتايج در جدول ب ارائه شده است.
همانطور كه مشاهده مىشود در مرحله بِ آزمون در كروه آزمايش ميانگين نمرات خود متمايزسازى افزايش و نمرات نكرانى از تصوير بدن و ترس از ارزيابى منفى شركت كنند گان كاهش داشته است و در گروه كنترل ميانگين نمرات شركت خود متمايزسازى، نغرانى از تصوير بدن و ترس از ارزيابى منفى شركت كنندگان تفاوت جندانى نداشته است. همجِنين براى بررسى نرمال

\begin{tabular}{|c|c|c|c|c|c|c|c|}
\hline توان & مجذور اتا & معنى سطح & $\mathbf{F}$ & درجه آزادى & فرضه شآزادى & مقدار & نام آزمون \\
\hline $1 / \cdot \cdot$ & $\cdot / V Y$ & $\cdot / \cdots 1$ & $9 / \pi T$ & ro & v & $\cdot / V Y$ & آزمون اثر بيلايى \\
\hline $1 / \cdot \cdot$ & $\cdot / N r$ &.$/ \cdots 1$ & $9 / \pi T$ & ro & v & $\cdot / T V$ & آزمون لامبداى ويلكز \\
\hline $1 / \cdot \cdot$ & $\cdot / V Y$ &.$|\cdots|$ & $9 / \pi \Gamma$ & ro & v & $r / 91$ & آزمون اثر هتلينك \\
\hline $1 / \cdot \cdot$ & $\cdot / V T$ & $\cdot / \cdots+1$ & $9 / \pi r$ & ro & $\checkmark$ & $r / 91$ & آزمون بزركىترين \\
\hline
\end{tabular}

كردن اينكه در كدام متغيرها تفاوت وجود دارد از تحليل كواريانس يكك راهه در متن مانكوا بر روى

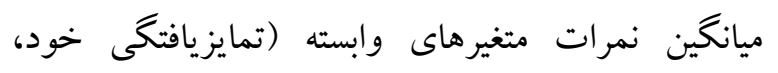
نكرانى از تصوير بلدن و ترس از ارزيابى منفى) استفاده شد كه نتايج آن در جدول F آورده شده است.
در جدول ب آورده شده است كه با كنترل ييش آزمون، سطوح معنىدارى همه آزمونها نشان مىدهد كه بين

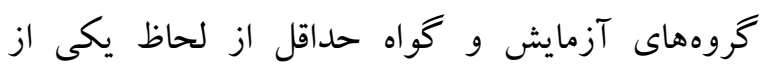
متغيرهاى وابسته (تمايزيافتكى خود، نخرانى از تصويتر بدن و ترس از ارزيابى منفى) تفاوت معنىدارى وجود

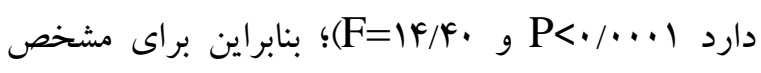




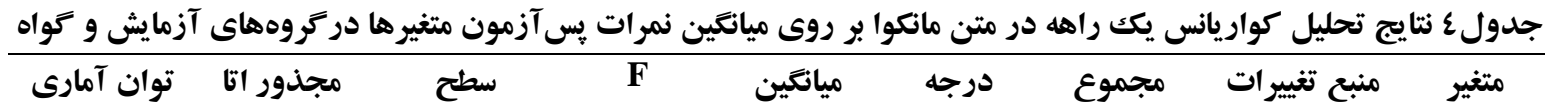

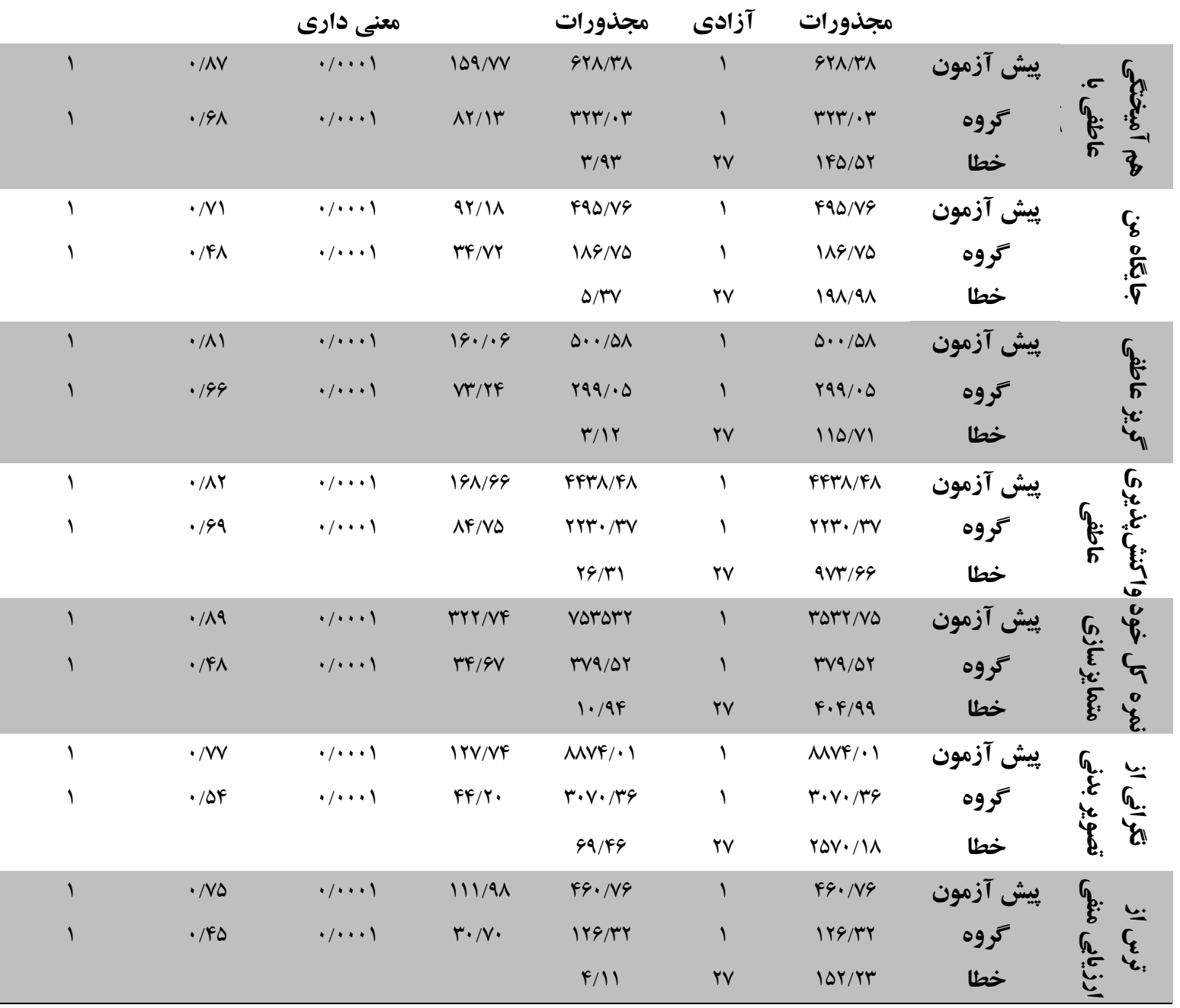

واكنشيذيرى عاطفى و تمايزيافتخى به طور كلى، در

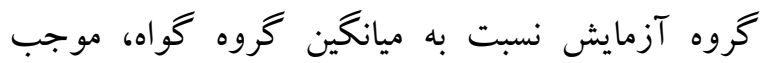

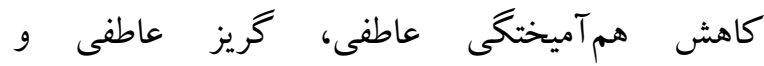
واكنشيذيرى عاطفى و افزايش جايگاه من و نمره كل تمايزيافتكى شده است. با كنترل بيش آزمون بين كروه

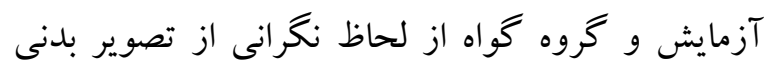

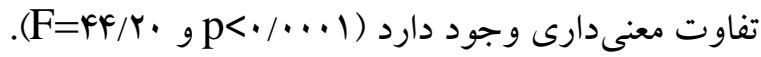
به عبارت ديخر، درمان مبتنى بر بذيرش و تعهد با توجه به ميانكين نكرانى از تصوير بدنى گرووه آزمايش نسبت به
همان طور كه در جدول F مشاهده مىشود با كنترل بيش آزمون بين گروه آزمايش و گروه گ گواه از لحاظ هم آميختكى عاطفى ( (F=人r/Ir) من ( , $p<\cdot / \cdots l)$

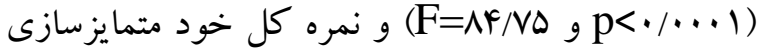

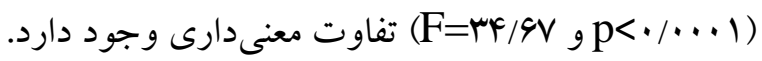
به عبارت ديخر، درمان مبتنى بر يذيرش و تعهد با توجه به ميانگين هم آميختخى عاطفى، جايخاه من، گريز عاطفى، 
(Y./Y) همسو و همخوان بود. در تبيين اين يافته مىتوان كفت كه با توجه به تكنيككايى كه در رويكرد بذيرش و تعهد مورد استفاده قرار مى گيرد مانند تمرينات مراقبهاى، تمرينات تجربهاى، استعارهها و قراردادهاى

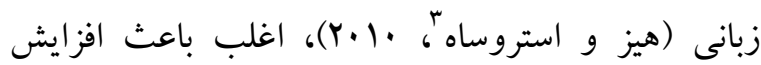

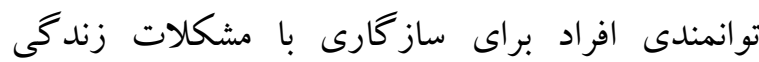
خواهد شد. اين رويكرد، باعث افزايش توانايى زندكى ستى در زمان حال و بهزيستى ذهنى مىشود و افراد در موقعيتهاى شديداً عاطفى و آشفته، از طريق افزايش تمركز بر زمان حال و بالا بردن سطح در گيرى منطقى و

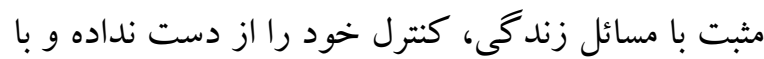
درنظر گرفتن عقل و منطق تصميم گيرى مى كنند، قادر به كنترل روابط هستند و به جاى تأكيد بر رفتارهاى آشفته هيجانى، بيشتر بر تجارب و ييدا نمودن راهحل متمركز

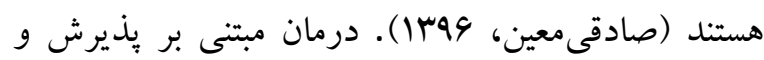
تعهل يك شيوه درمانى است كه با استفاده از آن مىتوان باعث افزايش بذيرش و انعطافيذيرى روانشناختى در فرد شد و در آن فرد، به جاى اجتناب از رويارويى با مشكلات و نخاه بيش داورانه و غرضورزانه به آن ها، با واقعيت ها روبه رو مىشود و با تأكيد بر يذيرش واقعيت، به كونهاى

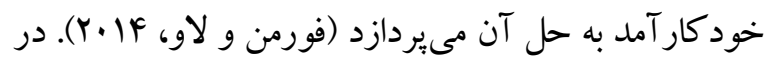
اين رويكرد به افراد كمكك مىشود تا واكنشهـا و افكار منفى را به شيوههاى جديد تجربـه كنــد و به مهار و

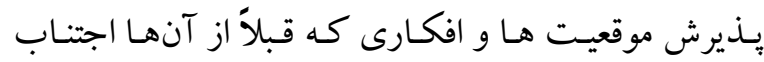

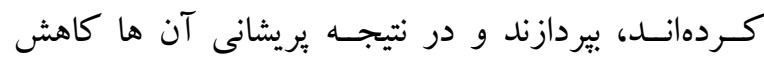

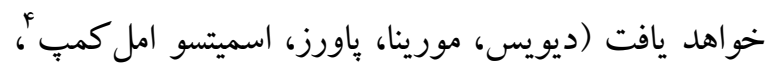

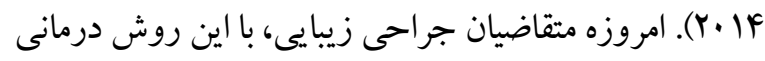
به دنبال حل مشكلات عاطفى و روابط بين فردى خود

${ }^{3}$ - Hayes \& Strosah

${ }^{4}$ - Davis, Morina, Powers, Smits\&Emmelkamp
ميانگين گرووه گواه، موجب كاهش نكخانى از تصوير بدنى كروه آزمايش شده است. همجينين با كنترل بيش آزمون، بين گروه آزمايش و كروه گواه از لحاظ ترس از ارزيابى منفى تفاوت معنىدارى وجود دارد

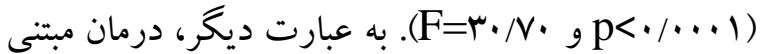
بر وِذيرش و تعهد با توجه به ميانگين ترس از ارزيابى

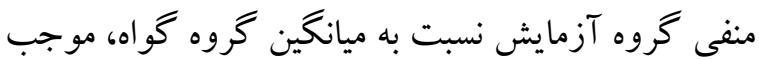
كاهش ترس از ارزيابى منفى گروه آزمايش شده است.

اين يثوهش با هدف بررسى اثربخشى مداخلات روش درمانى مبتنى بر بذيرش و تعهد بر تمايزيافتكى خود،

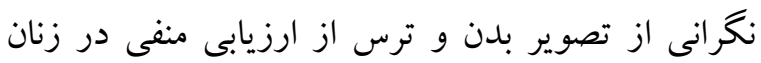

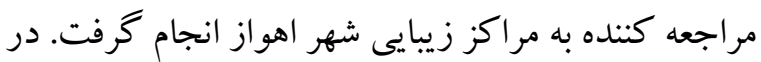
ذيل نتايج به دست آمده مورد بحث و بررسى قرار مى كير د. با توجه به نتايج به دست آمده، مشاهده مى گردد كه با

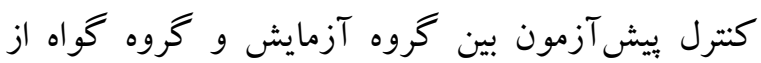
لحاظ تمايزيافتخى خود تفاوت معنىدارى وجود دارد. به عبارت ديخر، درمان مبتنى بر يذيرش و تعهد با توجه به ميانگين تمايزيافتكى خود در گروه آزمايش نسبت به ميانگين گروه گواه، موجب افزايش تمايزيافنكى خود در

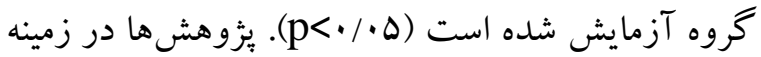
موضوع حاضر بسيار محدود بود. نتايج بثوهش حاضر به صورت مستقيم و غيرمستقيم با يزوهششاى صادقىمعين

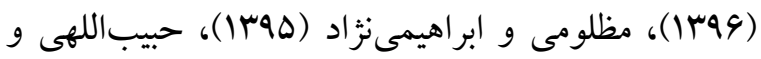

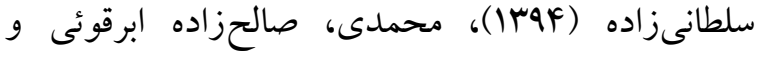

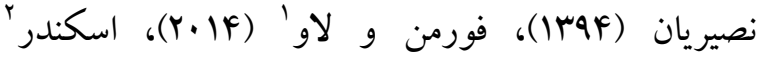

\footnotetext{
1 - Forman \& Lowe

2- Skandar
} 
و بر طرحواره هاى مرتبط به شكل، وزن، ظاهر بر فرايند اطلاعات دربارهى تصوير بدنى اثر مى كذارد. نارضايتى از تصوير بدنى، باعث افكار بريشان كنندهاى خواهد شد كه منجر به قضاوتهاى منفى فرد از خود و رفتارهاى ديخران خواهد شد و در نتيجه اعتماد به نفس فرد را مخدوش مىسازد. اين افكار باعث ايجاد رفتارهاى آشفته مانند دورى، اجتناب از روابط بين فردى خواهد شد (خانجانى و

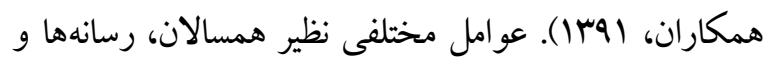
... در تصوير بدنى و توجه به ظاهر خود، تأثير دارند و افراد را تحريك مى كنند كه به جذابيت ظاهرى خود توجه كنند نه به صفات درونى. ارزيابى افراد از خود تحت تأثير بازتابهاى ذهنى و طرز تفكر آنها نسبت به خودشان است

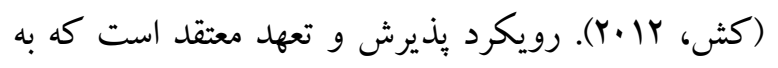
محض آنكه تجارب خصوصى (افكار، تصورات، احساسات، خاطرات و طغيانهاى درونى) برجسب مى خورند، بلادرنگ نزاع و كشمكشى با آنان شروع مىشود؛ زيرا علائم به عنوان يكك موضوع آسيبزا و مرضى معنى مى گردند (آنجه كه ما تلاش مى كنيم از آن خلاص شويم). درمان مبتنى بر بذيرش و تعهد ارتباط بين افكار و احساسات مشكل زا را تغيير مىدهد تا افراد آنان را به عنوان علائم مرضى درك ننموده و حتى ياد بحيرد كه آنها را بىضرر

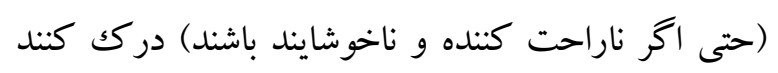

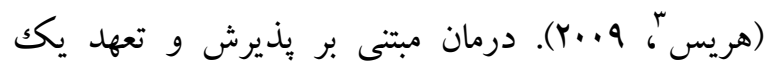

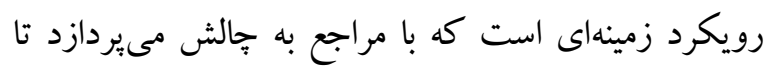
افكار و احساسات خود را بذيرفنه و نسبت به تغييرات متعهد كردد. يافته يُوهش نشان مىدهد كه با كنترل ييش آزمون بين

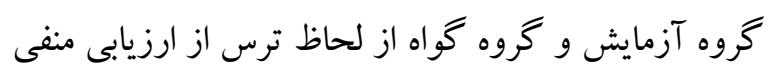

${ }^{3}$ - Harris
هستند. درمان مبتنى بر تعهل و بذيرش بر مبناى يذيرش، روبه

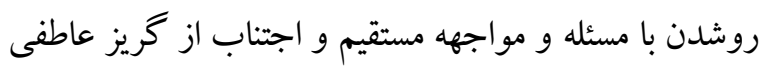

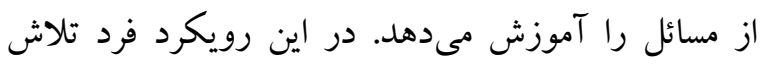
مى كند كه خود به طور مستقيم به حل منطقى مسئله بيردازد و از راهبردهاى ساز كارانهاى به حل مسئله بيردازد، تصميم گيرى بر اساس هيجانات، فرد را به سمت بِاك كردن صورت مسئله و اتخاذ شيوههاى ناساز گارانه حل مسئله نظير تصميم براى جراحى زيبايى سوق خواهد داد (عباسزاده و

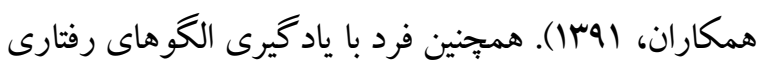
جديد و مهار موقعيتهاى قبلى كه در آن به شيوهاى ناكار آمد تصميم گيرى مىنموده، حس روشنترى از خود، خواهد داشت و جايگاه من در فرد تثيت خواهد شد. در نتيجه اين درمان، به جهت ايجاد آكاهى لحظه به لحظه از تمام رفتار و اعمال، توجه به مسائل و تلاش براى حل آن، به فرد كمكك خواهد كرد كه حتى در روابط بين فردى منطقى عمل نموده، مسئوليت اعمال خود را يذيرفته و استقلال خود را حفظ نمايد (اين، Y. Y. Y). با توجه به نتايج به دست آمده، مشاهده مى كردد كه با كنترل

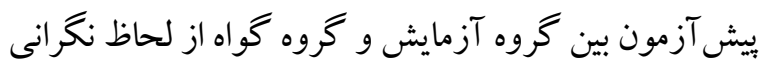
از تصوير بدن تفاوت معنىدارى وجود دارد. به عبارت ديخر، درمان مبتنى بر بذيرش و تعهد با توجه به ميانگين

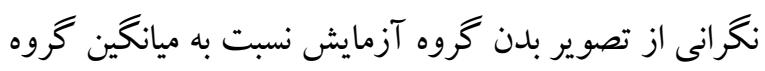
گواه، موجب كاهش نخرانى از تصوير بدن گروه آزمايش

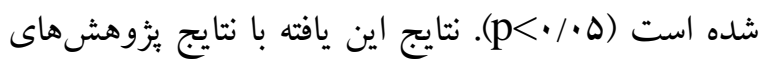

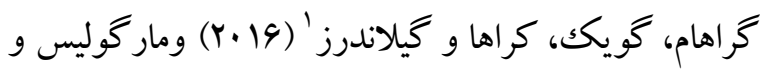

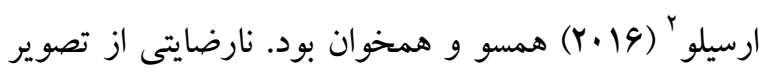
بلدى يكك سازهى يبيجيده از تصوير ذهنى دربارهى اندازه،

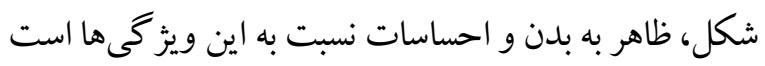

\footnotetext{
1- Graham, Gouick, Krahé \& Gillanders

${ }^{2}$ - Margolis \& Orsillo
} 
بشناسد و به طور واضح مشخص سازد و آنها را به اهداف رفتارى خاص تبديل كند. همجنين در جلسات بعدى كه بر افزايش آكاهى روانى تمركز مىشود، افراد نقاط مثبت و منفى خود را دوباره مورد سنجش قرار مىدهند و سعى مى - كـى كنند قضاوت درستى در مورد مشكلات خود بكنند. رويكرد يذيرش و تعهد درمانى به جاى آن كه روى برطرف سازى و حذف عوامل آسيبزا تمركز نمايد به مراجعه كنند كان كمك مى كند تا هيجانات و شناخت هاى كنترلشده خود را بيذيرند و خود را از كنترل قوانين كلامى كه سبب ايجاد مشكلاتشان شده است خلاص نمايد و به آنها اجازه مىدهد كه از كشمكش و منازعه با آنها دست بردارند.

\section{نتيجه كيرى}

يافتهاى اين يزوهش نشان داد، درمان مبتنى بر بذيرش و و

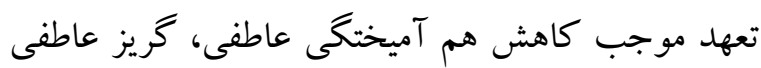
و واكنش يذيرى عاطفى و افزايش جايگاه من و نمره كل

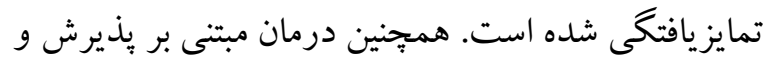
تعهل با توجه به ميانگين گروه آزمايش نسبت به گروه كواه، موجب كاهش نگرانى از تصوير بدن و ترس از

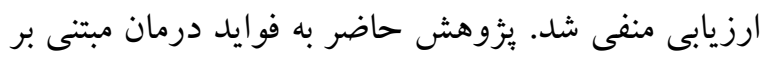
يذيرش و تعهد بر كاهش تصميم گيرى براى جراحى زيبايى با زمينهاى عاطفى و شناختى اشاره كرد. از محدوديت اين يزوهش، محدود بودن نمونه يزوهش به مراجعه كنند كان به مراكز زيبايى اهواز، عدم وجود مرحله ييخيرى و استفاده از يرسشنامه در جمع آورى دادهها بود. اين محدوديتها تعميميذيرى يافتها را با محدوديت

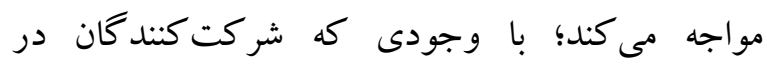

تفاوت معنى دارى وجود دارد. به عبارت ديخر، درمان مبتى بر بذيرش و تعهد با توجه به ميانكين ترس از ارزيابى منفى كروه آزمايش نسبت به ميانكين گروه گواه، موجب كاهش

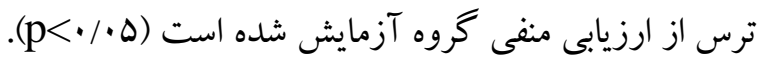
نتايج اين يافته با نتايج يثزوهشهاى حبيباللهى و و سلطانىزاده ( (1) )، محمدى، صالحزاده ابرقوئى و نصيريان

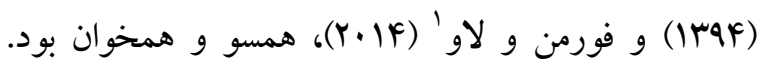
ترس از ارزيابى منفى و اضطراب ناشى از آن، سبب اجتناب

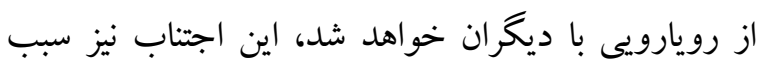
محدوديت تجربه افراد در روابط اجتماعى و ناكار آمدى در روابط اجتماعى خواهد شد. اين سيكل معيوب ادامه يافته و ترس از ارزيابى منفى را افزايش مىدهد (بريتو و همكاران،

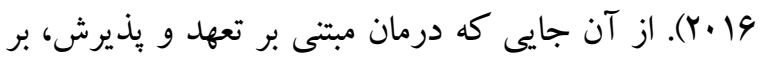
مواجهه منطقى و عدم آشفتگى هيجانى تأكيد دارد و افراد را تشويق مى كند كه با ارزشهاى واقعى زندگى خود بيوند يابند و مجذوب آنها گردند، اين تمرينات كمك مىنمايند تا فرد مستقيماً با وقايع استرسزا و تنشزاى خود خصوصاً در جلسات درمانى تماس بيدا كند و افكار و هيجانات نامطلوب را به جاى كنترل و يا كشمكش با آنها، تجربه نمايد. فرد به طور كامل افكار و هيجانات مربوط به تصور بدنى خود را تجربه مى كند. در نهايت اين درمان، باعث كاهش نكرانى از تصوير بدن و ترس از ارزيابى منفى

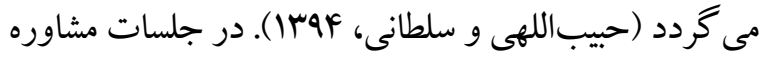
مبتنى بر بذيرش و تعهد كه انعطافيذيرى روانى، آكاهى روانى، جداسازى شناختى آموزش داده مىشود. جداسازى شناختى باعث مىشود افراد، مشكلات خود را از بيرون بييند و راحت تر در مورد مشكلات خود حرف بزنند و اين به فرد كمك مى كند تا اينكه ارزشهاى شخصى اصلى خود را

\footnotetext{
1. Forman \& Lowe
}

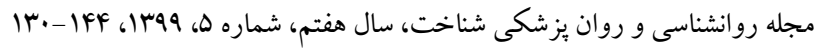


abdominoplasty. Aesthetic Surgery Journal, 36, 324-332.

Cash TF, Santos MT, Williams EF. (2005). Coping with body- image threat and challenges: Validation of the body Image coping strategies Inventory. Journal of Psychosomatic Research, 58(2), 191-199.

Cash TF. (2012). Cognitive-behavioral perspectives on body image. Encyclopedia of Body Image and Human Appearance, 3(2), 334-42.

Davis M, Morina N, Powers M, Smits J, Emmelkamp P. (2014). A meta-analysis of the efficacy of acceptance and commitment therapy for clinically relevant mental and physical health problems. Psychotherapy and Psychosomatics, 84(1), 30-6.

Dori Jani T, Ebrahimi Nejad Gh. (2015). Relationship between concern about body image and selfesteem (academic and social) with social anxiety. Intemational Conference on Psychology and the Culture of Life, Istanbul, July. (In Persian).

Dowling NA, Jackson AC, Honigman RJ, Francis KL. (2011). Psychological characteristics and outcomes of elective cosmetic surgery patients: the influence of cosmetic surgery history. Plastic Surgery Nurses, 31(4), 176-84.

Ebben WP. (2014). Body image as a motivator and barrier to exercise participation. International Journal of Exercise Science, 3(1), 14-24.

Eskandar M. (2013). Correlation of perceived body image and physical activity in womenand men according to the different levels of Body Mass Index (BMI). Journal of Health Promotion Management, 2(2), 59-70.

Fakuri Joybari Z, Hassanzadeh R, Abbasi Gh. (2019). The effectiveness of treatment based on acceptance and commitment to selfdifferentiation and mental health of veterans' children. Joumal of Social Health, 6 (3), 326314. (In Persian).

Forman EM, Lowe MR. (2014). Efficacy of an acceptancebased behavioral intervention for weight gain prevention in young adult women. Journal of Contextual Behavioral Science, 3(1), 45-50.

$$
\begin{aligned}
& \text { بثزوهش حاضر همكى رضايت كتبى شر كت در آزمايش }
\end{aligned}
$$

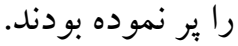

$$
\begin{aligned}
& \text { سياسگز ارى } \\
& \text { بدينوسيله از بزشكان و متخصصين جراحى بلاستيك } \\
& \text { شهر اهواز و كليه شركت كنند كان در يُزوهش كه ما را } \\
& \text { در اجراى اين بثزوهش يارى رساندند، صميمانه تشكر و }
\end{aligned}
$$

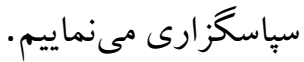

\section{References}

Abbas OL, Kukcuoglu A, Aytop CD, Uysal C, Pelin C. (2017). Perception of symmetry in aesthetic rhinoplasty patients: Anthropometric, demographic, and psychological analysis. Perception, 46, 1151-1170.

Abbaszadeh M, Aqdasi Alamdari F, Saadati M, Mubarak Bakhshaish M. (2012). Sociological study of the tendency to beauty with plastic surgery and related factors. Journal of Applied Sociology, 23 (3), 140-123. (In Persian).

Alavi M, Kalafi Y, Dehbozorgi GR, Javadpour A. (2011). Body dysmorphic disorder and other psychiatric morbidity in aesthetic rhinoplasty candidates. Journal of Plastic, Reconstructive \& Aesthetic Surgery, 64, 738-741.

Askian P, Sanaei Zakir B, Nawabi Nejad Sh. (2008). Investigating the effect of psychodrama on the increase in individual segregation from the main family in high school female students in District 5 of Tehran. Counseling research (news and counseling research), 7 (25), 27-42. (InPersian).

Azali Alamdari K, Azaryan S, Ghorbanzadeh B, Khoshnevis F. (2016). Figure rating and body appreciation in sedentary and those women present in sport activities from Tabriz City. JHPM, 5(3), 1-14. (In Persian).

Brito MJ, Nahas FX, Cordas TA, Gama MG, Sucupira ER, Ramos TD. (2016). Prevalence of body dysmorphic disorder symptoms and body weight concerns in patients seeking 
Graham CD, Gouick J, Krahe C, Gillanders D. (2016). A systematic review of the use of Acceptance and Commitment Therapy (ACT) in chronic disease and long-term conditions. Clinical Psychology Review, 46, 46-58.

Habibollahi A, Soltanizadeh M. (2016). Efficacy of Acceptance and Commitment Therapy on Body Dissatisfaction and Fear of Negative Evaluation in Girl adolescents with Body Dysmorphic Disorder. J Mazandaran Univ Med Sci, 25 (134), 278-290. (In Persian).

Harris R. (2009). ACT made simple: Aneasy-toread primer on acceptance and commitment therapy. Oakland, CA: New Harbinger Publications. (pp. 3-29). New York, NY: Springer ScienceBusiness Media.

Hasker SM. (2010). Evaluation of the MindfulnessAcceptance-Commitment (MAC) approach for enhancing athletic performance. Dissertation for the Degree Doctor of Psychology, University of Pennsylvania.

Hayes SC, Strosah KD. (2010). A practical guide to acceptance and commitment therapy. New York: Springer science and business media Inc.

Hayes SC. (2008). Acceptance and commitment therapy, relational frame theory, and the third wave of behavioral and cognitive therapies. Behavior Therapy, 35(4), 639-665.

Kavousian J, Haniffi H, Karimi K. (2017). The Efficacy of Acceptance and Commitment Therapy (ACT) on Marital Satisfaction in Couples. JHC, 19 (1), 75-87. (In Persian).

Khanjani Z, Babapour J, Saba G. (2012). Investigating Mental Status and Body Image in Cosmetic Surgery Applicants in Comparison with Nonapplicants. JSSU, 20 (2), 237-48. (In Persian).

Khazir Z, Dehdari T, Mahmoodi M. (2014). Attitude of female medical students towards cosmetic surgery and its relation with body image. RJMS. 20(117), 1-9.(In Persian).

Kranian F, Kakabarai K. (2015). Investigating the relationship between differentiated and variable variables in nurses in Kermanshah city. 3rd Intemational Conference on
Psychology and Social Sciences, Tehran, October.(InPersian).

Leary RM. (1983). A Brief version of the fear of negative evaluation scale. Personality and Social Psychology Bulletin, 9(3), 371- 375.

Lipowska M, Lipowski MZ, Olszewski H, DykalskaBieck D. (2016). Gender differences in bodyesteem among seniors: Beautyand health considerations. Archives of Gerontology and Geriatrics, 67 (1), 160-170.

Littleton HL, Axsom DS, Pury CL. (2005). Development of the body image concern inventory. Behavior Research Thrapy, 43(2), 229-241.

Margolis SE, Orsillo SM. (2016). Acceptance and Body Dissatisfaction: Examining the Efficacy of a Brief Acceptance Based Intervention for Body Dissatisfaction in College Women. Behavioural and cognitive psychotherapy, 44(4), 482-92.

Mazlumi N, Ebrahimi Nejad Gh. (2016). Determining the effectiveness of a commitment-based group treatment approach and accepting the nose-raising of mothers with children with a leaming disability problem in middle school. World Conference on Psychology and Educational Sciences, Law and Social Sciences at the Beginning of the Third Millennium, Shiraz, March. (In Persian).

Mohammadi L, Salehzade Abarghoei M, Nasirian M. (2015). Effectiveness of Acceptance and Commitment Therapy on Cognitive Emotion Regulation in Men under Methadone Treatment. JSSU, 23 (9), 853-861. (In Persian).

Mohammadi N, Sajjadinejad MS. (2007). Concerns about body image fear of negative evaluation and self-esteem with social anxiety. Joumal of Modern Psychological Research, 16 (5), 7055. (In Persian).

Sadeghi Moein F. (2017). The effectiveness of groupbased acceptance and commitment therapy training on the differentiation of individual well-being and living in the present. Master Thesis, Shahid Bahonar University, Kerman. (InPersian). 
رضوان همائي و همكاران IFF

Sahebalzamani M, Chale Chale Kh, Farahani H. (2018). Data for the level of women's selfesteem and couples' sexual satisfaction before and after mammoplasty. Data in Brief, 19 (1), 2344-2347.

Sharifi K, Masoudi-Alavi N, Tagharrobi Z, Sooki Z, Asgarian FS, Akbari H. (2011). Relationship between mothers' and daughters' self-esteem. Feyz, 15(4), 352-358. (In Persian).

Shokri O, Geravand F, Naghsh Z, Ali Tarkhan R, Paeezi M. (2008). The Psychometric Properties of the Brief Fear of Negative Evaluation Scale. IJPCP, 14 (3), 316-325. (In Persian).

Skowron E, Friedlander M. (1998). The differentiation of self inventory: development and initial validation. Journal of Counseling Psychology, 28, 235-246.

Skowron EA, Dnday AK. (2004). Differentiation of self and attachment in adulthood: Relational correlates of effortful control. Contempoary Family Therapy an Intemational Journal, 26, 337-357.

Skowron EA. (2000). The role of differentiation of self in marital adjustment. Journal of Counseling Psychology, 47, 229-237.

Sweis IE, Spitz J, Barry DR, Cohen M. (2017). A review of body dysmorphic disorder in aesthetic surgery patients and the legal implications. Joumal of Plastic, Reconstructive and Aesthetic Surgery, 41, 949-954. 